\title{
Assessment as Seen from the Albanian EFL Teachers' Perspective
}

\author{
Laureta Vavla \\ Aleksander Xhuvani University \\ Email lauretavavla@yahoo.com
}

\section{Doi:10.5901/ajis.2012.v2n4p263}

\section{Abstract:}

This paper is the result of a continuous four-year research in the field of assessment and evaluation. The object of this study were seven teachers in the Elbasan district who teach English in the elementary school level. Through a set of interview questions the teachers have been critically engaged in the analysis of their assessment practices, their success stories and the challenges they encounter in their everyday work. As such, this article aims at giving a correct portray of assessment issues today and the needs analysis the teachers themselves have made regarging this crucial element in teaching foreign languages in general and English in particular. Hence, this study constitutes a modest contribution that should serve as an incentive for the student teachers, current teachers and university lecturers so as to refocus their attention on this area.

Key Words: Assessment, teaching, learning

"For many students, assessment is not an educational experience in itself, but a process of 'guessing what the teacher wants., (McLaughlin \& Simpson, 2004)

\section{Introduction}

Assessment has become a buzz word in today's world but its importance in foreign language teaching still needs to be further developed. It is definitely true that "if we wish to discover the truth about an educational system we must look into its assessment procedures". (Rowntree, D.,1987). But are Albanian students, teachers, parents and other stakeholders actually referring to assessment? In reality they are not. "If all other elements of the course point in one direction and the assessment arrangements in another, then the assessment arrangements are likely to have the greatest influence on the curriculum" (Erwin, T D, and Knight, $\mathrm{P}$, 1995). Hence, teachers and students together should closely collaborate in order to use the information collected through assessment tools so as to further develop their language capacities and skills. But the clashes between the teachers' and the student's perspective on this area continue to clash. As Kandlbilder states, from the students' perspective it is only the most important activities in a subject that are assessed (Peter Kandlbilder, 2009). But do the teachers feel the same? This is the question whose answer this study seeks to find.

\section{The study}

This study aims to investigate the different perspectives on assessment and testing of seven teachers in seven different schools in the Elbasan district who teach English in the elementary school level. All the teachers have graduated in English and their age ranges between $23-42$ years old.

\section{Data Analysis}

The data was analyzed according to the responses obtained from the participants. The interviews were conducted individually with each and every teacher. The data collected were analyzed and evaluated and 
teachers were monitored in their classes through observation classes during these four year period of research.

The interviews conducted with the teachers aimed to collect a more elaborate and specific information than that collected by the observations. Due to the fact that technically it was impossible to interview the large number of teachers working in the Elbasan district, this study was limited to interviewing seven teachers who were directly part of the research study and who had collaborated with the researcher over a considerable period of time.

In these interviews, teachers were asked questions about the importance they gave to assessment in their teaching, the assessment type/s they practiced and the frequency of these assessment procedures. The Common European Framework of Reference for Languages had a crucial role in the interviews focusing more on the impact of the framework on teaching in general and on assessment in particular. Teachers were also asked to give feedback on the potential, necessary improvements that they desire to see in the assessment of their students. Their thoughts have been summarized in the following section of this article.

First question: Please, can you specifically explain the reasons why you assess your students?

Many teachers responded that they assessed their students because it was necessary and indispensable. Students had to be given a grade based on the various exams planned to be organized by the teachers as well as based on the students' "weekly preparations". All the teachers directly linked assessment to the need of grading their students as this was one of their duties as teachers.

Two of the interviewed teachers considered assessment not only as a tool they used to put grades but they also believed that assessment assisted them in managing the teaching process itself. The second reason why they assessed was directly linked to themselves as teachers. They said that "if students do not achieve good results at the end of an assessment carried out then the fault is not just of the students. In many cases the 'fault' lies with the teachers and their teaching. It is impossible for a high percentage of students to achieve poor results in assessment if whether the teacher has given more of himself in the process of teaching and learning ". To them, assessment was a mutual reflection, on one hand it served to the students who reflected on their learning and on the other hand (which is often more important) it served to the teachers, who simultaneously should reflect on the advantages and shortcomings of their teaching.

Boud has clearly stated that "assessment can encourage passive, reproductive forms of learning while simultaneously hiding the inadequate understanding to which such forms of learning inevitably lead. In some cases courses tend neither to develop basic concepts well, nor use assessment tasks which allow staff or students to know whether concepts have been learned." (Boud, D, 1995). Therefore, teachers have to think more on the reasons why they assess and develop their learning based on these leading purposes.

Second question: How does assessment influence in your students' academic preparation?

The answers gathered were generally the same among respondents. They said that the impact that assessment had on their students often changed depending on the level of language proficiency. Thus, respondents generally distinguished two large groups of students, the advanced and the elementary students. According to the interviewed teachers, the first group viewed assessment as a good opportunity to analyze their skills and capacities in English at a specific time; whereas the second group of students viewed this process as a very dark moment in teaching and learning, a moment when they had to go through 'hell'. According to them, there also is a category of students who put so much pressure on themselves when assessed that they even end up forgetting everything they have seriously learned.

The respondents further stated that students were generally incited to learn more especially when they were notified to have an exam. The examination period marked a moment when most students including the 'lazy' ones, turned into diligent students in order to achieve slightly better results in the exam. What many teachers mentioned is that in these cases, but not only, there is mechanical and reproductive learning happening in the students. They often memorize certain parts of the text, but without understanding the text itself and without understanding the inner logic of connecting those precise words in the text.

However, the general ideas given were that assessment was an impetus for the students to learn more, however, this incentive cannot be considered highly effective because we are talking about a foreign 
language, which students can not however learn one day before examination. Knowledge should be gained systematically and being that assessment, in one way or the other serves as a motivation to the students it would be good according to the teachers, for assessment to be seen as an integral part of everyday teaching and not be sporadic in nature. Theoretically, continued the teachers, a systematic assessment would lead to a systematic learning. But this theory does not apply in the Albanian reality and the reasons are various. In the list below you can find some of the reasons cited by the teachers:

- The large number of students in class.

- Difficulty in managing the amount of materials to asses

- Lack of clear assessment procedures

- Overloaded textbooks

- Limited number of English classes per week etc.

If most of these factors would be eliminated or minimized, then it would be very easy for the teachers to periodically and correctly carry out assessment.

Third question: How do you assess your students?

The answers to this question were numerous but we have tried to summarize some typical elements. Many of the respondents based their assessment on the students' performance in the latter exams and tests that teachers developed throughout the semester. To these teachers, tests mattered a lot, they were considered a very effective tool for teachers to gather the information they needed in order to establish a clear idea so as to assess their students. According to them, the test results in most cases fully coincided with the assessment that students were sporadically given during school hours, but there were times when in certain exams, for a reason or another, students received lower grades (and/or sometimes higher ones!!!). However, they continued, assessment through examinations or tests was very important, and despite the burden of correcting them, teachers ultimately needed such exams.

During the interview sessions, the seven teachers interviewed indicated that the assessments conducted did not contain a particular assessment rubric and in reality this assessment was and could be highly subjective. Given that teachers were not offered a ready-made model of each weight division of language skills, they were resilient during the evaluation of their students. The percentage that each language skill carried changed depending on the type of examination or assessment being applied and on the moment when this assessment took place. After thoroughly reflecting on this issue, all of the interviewees stated that a standard assessment rubric would be very helpful to them so as to give somewhat the same if not identical assessment to their students. A student who qualifies as an advanced one for a teacher by using a certain assessment rubric would result as such even by the other teachers using the same rubric. Who the teacher is and who the student is would become irrelevant. In the absence of these rubrics, different students are assessed differently in case they change their class, their school or even their language teacher. According to the respondents, the lack of rubrics was the main reason that lead to subjective assessment.

As one of the interviewees stated "it is necessary for teachers to unify their assessment criteria, because only through well defined assessment rubrics and recognized in advance by the students will we be able to achieve an objective and uniform assessment of the students whenever, wherever and whoever they are assessed from." By doing so, teachers will be able to avoid various clashes between stakeholders in education: students, parents, principals, and teachers. The burden that is imposed on the teachers in providing assessment is greatly facilitated if there are used similar criteria in assessing learning. "Only then will the law 'be equal for all", - said one of the respondents.

The next question: What kind of assessment articles do you focus more on assessment?

Many of the teachers answered 'unanimously' that they focused more on the lexical and grammar exercises as well as in reading and writing skills. They argued that without a strong grammatical foundation a student could not create correct sentences and therefore the teachers were obliged to stress and focus more on this linguistic element compared to the others. On the other hand, they claimed that a child, who was able to correctly articulate his ideas and thoughts in speech, had reached a high level of training in the language and therefore he could be capable of expressing himself in writing as well. One of teachers stated: "I want to 
emphasize that we as teachers are more accurate in assessing the written work because our teaching is also focused or writing too more than on the other skills."

The weight that speaking and listening constitute in assessment was lower compared with the reading, writing, grammar and vocabulary elements. A basic reason given by the teachers for this phenomenon was the fact that due to the large number of students in the class it was easier for a teacher to assess these elements rather than assess the speaking or the listening skills of the students. Speaking was a skill, which according to the teachers could not be practiced by all their students within a limited timeframe of 45 minutes per class. Meanwhile exercises in writing, grammar, vocabulary and silent reading or offered to the teachers the opportunity to engage a greater number of students.

In connection to the listening skill, all the teachers pretended that it was unlikely for these activities I exercises to be performed in class, because schools generally lacked the necessary infrastructure, audio was nonexistent in many schools. Moreover none of the teachers interviewed had the chance to work in a foreign language laboratory in their school, where these activities could easily take place and listening activities could have been quite effective. Listening exercises in a classroom with 35 and more students is not possible because the students seating at the back of the class can not hear anything. Class management of in such conditions also constitutes a prime concern over the development of such activities.

Two of the teachers interviewed said they had practiced listening at least once in their classes and had noticed that it was almost impossible for their students to understand what they were listening to and for this reason these teachers had not continued on the implementation of these exercises since the time 'lost' in these activities was significant.

The following question: What do you see in students' errors when you evaluate them. Which skills present more difficulties to the students?

Many teachers said that their students make mistakes in grammar issues, in word order and the correct spelling of the words in the English language due to the nature of this language in writing. Many of the respondents thought that grammatical errors are present because students lack the understanding of grammatical concepts in Albanian and consequently many of them exhibit these problems in English too. Problems in the sentence word order again arise somehow naturally due to the huge differences that these two languages (Albanian and English) represent in this regard.

The writing skill again is considered by the teachers as a problematic element not only in English but also in Albanian because there is a shortage of unified guidelines about different types of writing assignments. The respondents support the idea that "it is appropriate and necessary at this point to intervene so that students are aware of the format and content of different types of writing in the Albanian language in order to reflect this recognition later on in their writings in English language".

Next question: Are the students notified about the ratings they receive during the semester. If yes, in what situations and conditions are the students declared these grades to?

According to the respondents, students were regularly informed about the results they achieved in exams or tests, when this was considered as necessary by the teachers, but also in evaluating the performance of the students' homework or class work and while filling out various exercises in class. Logically, some students were assessed negatively particularly in those cases when the latter were not prepared in advance at home, especially when this behavior was repetitive. Punishment with a negative grade was necessary for the teachers - they said, because this way students were generally obliged to study more in the future.

To the question: Are you trained in techniques and different types of assessment of your students?

Unfortunately we were informed that many of the teachers were not provided with any proper training in this regard. In the initial stages of their English language teaching profession they had consulted their colleagues at their school or in other schools about teaching and assessment in general. After that, they had acted individually making their choices depending on their students' learning and the different situations presented. According to them it is "work experience that teaches one how to assess". 
However, given that some of the respondents had graduated from a Master's of Science and/or a Professional Master's in Teaching, we found that these teachers had some updated insights gained in the university auditoriums about various issues related to teaching and some of them stated that it was especially during their professional practicum that they were practically informed about the assessment process in particular. It remains a fact that the role of assessment had not received a great deal of attention by university lecturers and teachers in the university level. The Professional Master's in Teaching program does not offer specific courses on assessment. Assessment issues are superficially and briefly covered in one or two lectures during Methodology classes.

It should be mentioned that, fortunately, in addition to the above factors, some of the respondents stated that they had participated in various conferences of teachers of English and sometimes they had attended in various sessions related to this topic, sessions that had raised their awareness about the role and impact that assessment has on the students, parents and society in general.

The following question: Are you familiar with the Common European Framework of Reference for Languages?

Teachers showed some reluctance at first, because they were not familiar with this important document for foreign languages in Europe. They were skeptical about the document and said they had not received specific instructions about it. The knowledge they had on the Common European Framework of Reference for Languages was a superficial knowledge basically due to their individual participation in postgraduate studies and in various conferences mentioned above. This fact was not at all positive!!!

The last question of the interview was: What would you recommend to improve assessment procedures for your students in the future?

This question had a wide range of responses. We have chosen to list some of them as follows:

- To have a smaller number of students in classes in order to work in groups.

- Assessment should be done in three ways: in writing, speaking and reading.

- Because the curriculum is too tight and overloaded a redesign of the syllabus would be the best thing to do.

- There need to be more English classes per week, so that students become easily familiar and accustomed with a foreign.

- Develop and unify several assessment criteria for students so as teachers and students are on the same track when it comes to conducting assessment.

- As discussed with other EFL teachers, there is speculation that it may be more efficient to use an expression remark of assessment such as very good, good, etc. rather than using grades. Personally, I would like the American system of assessment:-A, A, A + etc.

- There is an urgent need for training in the field of assessment so that all teachers are well informed on this key element in teaching and we all use the same "identical ruler to measure" our students.

\section{Conclusion}

As seen from the data collected above, teachers are aware that assessment is an important component of teaching and learning and therefore measures should be taken for this process to be unified by setting clear criteria of assessment to be used throughout all the country. It can also be easily noted that teachers associated the problems they encounter in assessing their students very closely with the teaching process and the problems this process mirrors. Nevertheless, it is positive to notice that it is the teachers themselves who have identified a gap in the field of assessment trainings and earnestly seek to fill this gap.

Through the responses collected it is emphasized once again the importance that continuous assessment plays in education. "As teachers, when we carry out assessment, we have to measure the performance of our students and the progress they make. We also need to diagnose the problems they have and provide our learners with useful feedback. (Harris and McCann, 1994)." This definition given by Harris and McCann clearly defines assessment as a measuring tool not only of the student's progress but also of the 
instructor's teaching. By diagnosing our student's problems, we can appropriately adapt our teaching methods and techniques to our learners. It is high time that assessment and teaching start to go hand in hand and contribute to the success of one-another. Changes are difficult to be made but mandatory to succeed. As Lee Trevino states « If you make a change and it feels comfortable, you haven't made a change. » ...

\section{References}

Boud, D (1995) Enhancing Learning Through Self-assessment. London: Kogan Page Brown, G, Bull, J dhe Pendlebury, M (1997). Assessing Student Learning in Higher Education. London: Routledge. Brown, H.D. (2004). Language assessment. Principles and classroom practices. White Plains, NY. Pearson Ed.

Bushman, L. \& Schnitker, B. (1995). Teacher attitudes on portfolio assessment, implementation, and practicability. (ERIC Document Reproduction Service No. ED388661)

Cohen, A. (1994). Assessing language abilitity in the classroom (2nd ed.) Boston

Cohen, L. Manion, L. and Morrison, K. (2000) Research Methods in Education (5th Edition). London: Routledge/Falmer.

Erwin, T D, dhe Knight, P (1995) "A transatlantic view of assessment and quality in higher education", Quality in Higher Education, 1 (2).

Harris, M. Dhe McCann, P. (1994) Macmillan Publishers Ltd

Rowntree, D. (1987). Assessing Students: How Shall We Know Them? London:Routledge Falmer. 